\title{
Mind over matter? \\ Multinational naval interoperability during Operation Iraqi Freedom
}

Stephen Paget

\begin{abstract}
The increasing frequency of multinational operations has heightened the importance of interoperability. While human and cultural factors are only two pieces of the interoperability jigsaw they are of enduring significance. The cohesiveness of the relationship amongst the Royal Australian Navy, the Royal Navy and the United States Navy during the 2003 Iraq War was underpinned by high levels of perceptive interoperability, which manifested itself in effective working relationships. That conflict demonstrated that while historical ties provided a foundation for cooperation, a number of multinational initiatives were undertaken to further enhance interoperability. This article addresses how such a high level of perceptive interoperability was achieved by examining the conduct of multinational exercises, the importance of personnel exchanges and the role of liaison officers, before considering the effect it had on the conduct of operations. The Iraq War demonstrated that cultural factors are at least as important as other facets of interoperability.
\end{abstract}




\section{Mind over Matter? Multinational Naval Interoperability during Operation Iraqi Freedom}

Air Commodore Chris Westwood, Royal Australian Air Force, stated: "When people talk interoperability, they often think immediately about the technical interoperability, but personally I think the technical interoperability is actually the easy part...It's the human side of interoperability which is the most important." The increasing frequency of coalition operations has ensured that interoperability is, and, will remain a foremost consideration for military planners. The revision and expansion of NATO's definition of interoperability is testament to the importance attached to the concept. Indeed, the requirement for interoperability is applicable to all services and transcends the nature of operations. Olivier Schmitt has noted: "Integration is the first, and probably the most obvious, problem in the case of coalition warfare."2

Analyses of interoperability during multinational military operations have often centred on land forces predominantly and have tended to be narrowly focussed. Contemporary interoperability, in reality, encompasses a multitude of factors that are interconnected. While they can be separated in a theoretical sense, they overlap in practice, ensuring that deficiencies in one area can undermine interoperability in another. Human and cultural factors may only constitute part of the interoperability matrix, but they are of enduring importance and they intersect with each other. Thomas Crowson has defined cultural interoperability as: "the ability of units from different nations, forces or organizations to understand, respect and operate with a shared understanding of each other's values, assumptions and national caveats in a synergistic attempt to achieve their respective national interests". ${ }^{3}$ Human interoperability, which includes a range of inter-personal factors such as relationships and liaison, is invariably shaped by 
Steven Paget

Forthcoming in Defense \& Security Analysis, 36:1, 2020. This is the post-print version and must not be copied or cited without permission.

cultural issues. ${ }^{4}$ Despite technological advancements and the onset of network-centric warfare, the significance of human and cultural interoperability has not diminished and has, in fact, arguably increased.

Scholars and practitioners are acknowledging increasingly the importance of the interpersonal aspects of interoperability, but there has been a distinct divergence in the terminology used..$^{5}$ The notion of "cognitive interoperability" - effectively a shared understanding - has led to the emergence of varying but overlapping terminology to encapsulate the concept; "cooperability" in the US, "interoperability of the mind" in the UK and "einheit im denken" [unity in thought] in Germany. ${ }^{6}$ While cognitive interoperability is a valid and important concept, the narrower meaning of perceptive interoperability - the ability to understand and respond to the intentions and actions of a multinational partner - may make it a more appropriate term for what is required as the base level for cooperation. In an ideal world, multinational partners would be of a like mind in all areas. In reality, however, an understanding of what a partner is thinking or how they will approach a problem is often sufficient for the planning and conduct of multinational operations.

The maritime operations conducted during Operation Iraqi Freedom (OIF) highlighted the importance of perceptive interoperability, even amongst the core of the naval coalition; most notably the Royal Australian Navy (RAN), the Royal Navy (RN) and the United States Navy (USN). ${ }^{7}$ Although maritime forces are generally regarded as being capable of integrating with greater ease than the other services and the RAN, RN, and USN are some of, if not the most cooperative navies in world, the high-level of interoperability demonstrated during OIF was achieved, in part, as a result of human and cultural factors. They should not be underestimated as it takes a significant of amount of time and effort to develop mutual understanding and productive personal relationships. 
Steven Paget

Forthcoming in Defense \& Security Analysis, 36:1, 2020. This is the post-print version and must not be copied or cited without permission.

A number of initiatives, including the conduct of multinational exercises, which are the foremost means of building multinational capacity; the exchange of personnel; and the deployment of liaison officers (LOs) have combined to generate a high-level of perceptive interoperability. OIF indicated that there were variations in culture and operating styles and it was the capacity of the navies to respond in an informed and understanding manner that helped to facilitate the cohesiveness and effectiveness of the multinational naval force. By addressing three of the most interoperable navies in the world and considering the effort that goes into sustaining their cohesion, it is possible to highlight the challenges that will be faced when less traditional partners are required to integrate. Indeed, a range of initiatives have been fundamental to the high-level of interoperability achieved by the "five eyes" countries (Australia, Canada, New Zealand, the UK and the USA), particularly the development of common doctrine and interchangeability in key areas. That has not, however, diminished the importance of perceptive interoperability.

This article will begin by considering the relevance of perceptive interoperability, before addressing the ways in which it can be furthered. By examining the conduct of multinational exercises, the exchange of personnel and the deployment of LOs, it is possible to discern the often-overlooked significance of perceptive interoperability during coalition operations. In the case of the naval effort during phase three operations in OIF between March and April 2003, which forms the basis of this article, it was clear that human and cultural factors helped to make the naval coalition more cohesive. There is no room for complacency, nevertheless, as it is far from inevitable that the upward trajectory in interoperability will continue, not least because technological advancements may diminish some of the improvements that have already been achieved. In addition, in an era of austerity, budget cuts may lead to reductions in personnel exchanges and, potentially, declining involvement in 
Steven Paget

Forthcoming in Defense \& Security Analysis, 36:1, 2020. This is the post-print version and must not be copied or cited without permission.

multinational exercises. It is important, therefore, to understand which measures have contributed to the development of perceptive interoperability and what action can be taken to improve it.

\section{Interoperability: A Worthwhile Challenge?}

Definitions of interoperability have been varied, but, NATO considers it:

the ability for Allies to act together coherently, effectively and efficiently to achieve tactical, operational and strategic objectives. Specifically, it enables forces, units and/or systems to operate together and allows them to share common doctrine and procedures, each others' infrastructure and bases, and to be able to communicate. ${ }^{8}$

The successful enactment of interoperability involves the capacity of equipment and personnel from different nations to work together both harmoniously and effectively. Basil Germond has pointed out that the rise of diverse transnational threats, the need for democratically elected governments to justify the deployment of military forces and financial constraints have converged to increase the appeal of multinational operations. ${ }^{9}$

The achievement of interoperability is no easy task. Lieutenant Colonel Chad Foster, US Army, has contended: "Interoperability is difficult and messy work, even among nations that have highly capable, professional military forces who are motivated to work together for a common cause." 10 Developing interoperability has often proven challenging, but it is a worthwhile endeavour. Increases in interoperability serve principally to improve the effectiveness of a multinational force. Interoperability can, in turn, help to reduce the risk faced by the fielded forces of different nations. At the most extreme end of the spectrum, interoperability can diminish the potential for friendly fire. Although the achievement of interoperability involves significant financial expenditure, the ability to share common burdens and leverage off coalition partners can help to reduce the potential costs of a given operation. 
Steven Paget

Forthcoming in Defense \& Security Analysis, 36:1, 2020. This is the post-print version and must not be copied or cited without permission.

Even when multinational cooperation is required as a flag-collecting exercise for political reasons, it is still important that military forces are able to operate together safely and effectively.

While analysts sometimes make reference to a common military culture or ethos, it is important not to over-emphasise inherent levels of unity. The Chief of Staff of the Multinational Force and Observers in Sinai in the mid-1990s noted: "As I learned very quickly when I arrived here, what I say to an American may not always be interpreted the same as if I say it to a Canadian, an Australian or a Fijian". ${ }^{11}$ A common military culture - even amongst navies which are generally regarded as the most cohesive of the services - does not lead to commonality. While different cultures are not in themselves problematic, it is important that militaries are able to adopt a common multinational mind-set during the conduct of coalition operations.

\section{Cultural Friction}

Cultural interoperability is especially important due to a variety of complex and interconnected factors and can "present challenges or opportunities". ${ }^{12}$ A multicultural force can provide increased political credibility, promote diverse inputs and solutions and facilitate interaction with host nations and adversaries. Cultural friction has, nevertheless, been an enduring challenge during multinational operations and has the potential to limit effectiveness and, possibly, undermine the mission. Even amongst nations that demonstrate cultural similarity there are still variations that can create tension. It has been noted that British and US forces "shared similar goals to fight the war and common cultural values" during the Second World War, but "learned habits from childhood translated into communication gaps that resulted in 
Steven Paget

Forthcoming in Defense \& Security Analysis, 36:1, 2020. This is the post-print version and must not be copied or cited without permission.

misplaced animosity". ${ }^{13}$ As the diversity of a multinational force increases so too does the potential for cultural friction.

A number of measures have been instituted to mitigate cultural friction, including the geographical separation of forces. During the United Nations Operation in Somalia (UNOSOM), for example, national contributions were separated by functional or geographic responsibilities, partly to avoid them having to cooperate with "other UN forces with whom national problems might emerge". ${ }^{14}$ The United Nations Interim Force in Lebanon (UNIFIL) mission at the Lebanon-Israel border was divided similarly into areas of responsibility, but it was observed that there were "limits in effectiveness" when "responsibilities of responding to incidents impacting the situation in other sectors are unclear, or are kept unclear for political reasons that go beyond military considerations only". ${ }^{15}$ Geographical separation may appear to be an obvious answer to cultural friction, but it is an imperfect solution. The creation of artificial boundaries can, aside from preventing a multinational force from showing "one face", lead to problems being moved to different areas rather than solved as opponents may seek to exploit variances amongst the forces, creating the potential for "spillover effects," and an inability to counter them due to an absence of "cross-border" operations. ${ }^{16}$

Joseph Soeters, Cristina-Rodica Poponete and Joseph Page Jr. have argued logically that "mutual accommodation" is the best approach in "intercultural encounters", because it promotes "true integration in which the best of many worlds are used and merged into something that is better than all previous contributing cultures". ${ }^{17}$ It has often proven difficult to achieve that solution despite it being optimal. When the Dutch company deployed to replace an element of Britain's contribution to the United Nations Peacekeeping Force in Cyprus (UNFICYP) in 1998 was placed under the British section commander, tension arose from a range of factors, including customs and traditions, which led to a suggestion that the soldiers 
Steven Paget

Forthcoming in Defense \& Security Analysis, 36:1, 2020. This is the post-print version and must not be copied or cited without permission.

should be confined to operating "within one's own tasks and responsibilities". ${ }^{18}$ In the case of the Multinational Land Force Brigade comprising forces from Italy, Hungary and Slovenia, Soeters and Tibor Szvircsev Tresch assessed: "Although Italy performed the role of the lead nation and, hence, set the standards of operations, the servicemen of the two other forces found it difficult to conduct their activities coherently with one another." 19 The problem is far from unique as evidenced by recent operations in Afghanistan. It was observed that Belgian and Canadian forces separated into two "blocs" and endured a frustrating experience, while "substandard cooperation" and "serious misunderstandings and conflicts" resulted from cultural friction between Dutch and German forces. ${ }^{20}$

Closer integration is increasingly becoming necessary for multinational forces, but a pro-active approach is required to mitigate any potential cultural friction. It is incumbent on the commander of a multinational force to "evaluate how a member of a cultural group...sees himself, determine what is important to him, and consider it when developing operational objectives, goals, and methods to achieve these operational goals". ${ }^{21}$ Multinational integration involves a process of "bonding and bridging" that encompasses the capacity to "overcome cultural barriers to international cooperation" and "an ability to harness cultural diversity as a positive asset, rather than a source of conflict". ${ }^{22}$ Although those skills sound relatively straightforward, cross-cultural abilities not only "take time to assimilate" as part of an ongoing process, but "there are no technological shortcuts". ${ }^{23}$

\section{Navies: Inherently Interoperable?}

Historian John Hattendorf has written: "Today, forming a coalition with other naval powers seems a basic and fundamental activity for navies." ${ }^{24}$ The extensive history of maritime cooperation and the continued requirement for navies to participate in multinational endeavours 
Steven Paget

Forthcoming in Defense \& Security Analysis, 36:1, 2020. This is the post-print version and must not be copied or cited without permission.

means that interoperability is a pressing concern. Integration of naval units into a task force is often easier than the challenges faced when assimilating land forces as ships are self-contained by their nature. ${ }^{25}$ The mobility of ships also provides a level of flexibility that enables them to engage in exercises and operations more frequently than other forces. The regular interaction amongst NATO naval forces during the Cold War created a platform for interoperability that is continually being refined. ${ }^{26}$ Germond has summarised:

[I]t is easy to amalgamate units from different nations to create a multinational task force. Indeed, the particular nature of the maritime milieu, with its freedom of manoeuvre and legality of action, grants naval forces a higher degree of flexibility and versatility than enjoyed by other armed services. ${ }^{27}$

Interoperability has, consequently, been seen as less challenging amongst maritime forces as a general rule. While many of the inherent advantages of naval forces help to facilitate interoperability, the process still requires good will and hard work. Divergences can be mitigated through the existence of strong and effective working relationships and high-level perceptive interoperability.

\section{OIF: The Naval Coalition}

The history of cooperation amongst the RAN, RN and USN in the Persian Gulf was extensive and underpinned the level of perceptive interoperability achieved during OIF. RN and USN commitments to preserve the freedom of movement for international shipping in the Persian Gulf during the Iran-Iraq War laid foundations that were built on by American, Australian and British involvement in Operations Desert Shield and Desert Storm. Prolonged interaction in the region, in addition to extensive multinational exercises and, in the case of the RN and USN, commitments such as Operation Sharp Guard in the Mediterranean, was fundamental to the cohesion achieved during OIF. The creation of the Maritime Interception Force (MIF), in 
Steven Paget

Forthcoming in Defense \& Security Analysis, 36:1, 2020. This is the post-print version and must not be copied or cited without permission.

particular, generated a platform for sustained interaction, with interception operations continuing after the cessation of Desert Storm in 1991. Efforts were intensified following the initiation of Operation Enduring Freedom (OEF), with 21 nations having contributed to the MIF by the commencement of OIF. ${ }^{28}$

The multinational nature of the MIF and the importance of the RAN and RN contributions were demonstrated by the command roles that they undertook. Rear Admiral James Burnell-Nugent (RN), Commander, UK Maritime Force (COMUKMARFOR), was appointed as the coalition deputy in October 2001. In exchange for the Australian contribution to maritime interception operations (MIO) during $\mathrm{OEF}$ and, in part due to the strength of personal relationships, commanders of the RAN task groups served as commander of the MIF group on a rotational basis with Commander, Destroyer Squadron 50 (COMDESRON 50) and, occasionally, the RN. ${ }^{29}$ The RAN, RN and USN, along with other coalition navies, had extensive experience operating together in the Persian Gulf by the commencement of OIF.

OIF saw the RAN and RN make valuable contributions to the naval coalition, including the fulfilment of leadership roles. The coalition command structure was complex and dominated mainly by USN officers for obvious reasons, but the RAN and RN were notably represented. In addition to his national command roles, Vice Admiral Tim Keating (USN), Commander, Fifth Fleet and Commander, US Naval Forces Central Command (NAVCENT) was "dual-hatted" as the Coalition Force Maritime Component Commander (CFMCC), which meant that both the USN and coalition command chains reported to him. ${ }^{30}$ Rear Admiral David Snelson (RN) served as Keating's coalition deputy after replacing Rear Admiral BurnellNugent as COMUKMARFOR in August 2002.

The remainder of the command structure was occupied by USN officers, with one 
Steven Paget

Forthcoming in Defense \& Security Analysis, 36:1, 2020. This is the post-print version and must not be copied or cited without permission.

notable exception. Rear Admiral John Kelly (USN) aboard USS Abraham Lincoln served as Commander, Task Force 50 (CTF 50) and Rear Admiral Barry Costello (USN), aboard USS Constellation, was appointed Commander, Task Force 55 (CTF 55), which made them responsible for naval air and surface operations respectively. The larger surface picture was divided into different areas and individual destroyer squadron commodores took command of particular areas. Commodore John Peterson (USN), COMDESRON 50, was appointed to the new role of Commander, Task Group (CTG) 55.1, making him the North Arabian Gulf Commander. ${ }^{31}$ The final rung of the coalition command chain was filled by an Australian, with Captain Peter Jones (RAN) serving as Commander, Task Unit (CTU) 55.1.1 - the MIO Screen Commander.

Naval forces made a number of contributions to the coalition effort throughout the conflict, including maintaining sea control, providing power projection and conducting maritime interception operations. Rear Admiral Costello later summarised: "The strength of the force in Operation Iraqi Freedom was significantly enhanced by our coalition partners. Their capabilities meshed with the U.S. warfighting expertise and, in several instances such as mine warfare, their skills and equipment were cutting edge. We learned from each other." ${ }^{32}$ The RAN and RN, ultimately, made important but not decisive contributions to the maritime campaign. The deployment of RAN and RN vessels and the integration of Australian and British officers into the command structure meant that interoperability was a pressing concern, irrespective of their contribution to the overall success of the campaign. ${ }^{33}$

The three navies had an extensive history of working together in the Persian Gulf, which led to a great deal of familiarity, but at the same time, the emergence of new equipment and innovative technology ensured that there was no room for complacency. The RAN, RN and 
Steven Paget

Forthcoming in Defense \& Security Analysis, 36:1, 2020. This is the post-print version and must not be copied or cited without permission.

USN demonstrated a high level of interoperability during OIF, which reflected, in part, the fact that the British and the Australians had become used to operating as the junior partner in coalitions with the Americans. It was also the result of a range of commonalities at the operational and tactical levels. Challenges remained, however, particularly in the realm of technical interoperability. The lack of Secret Internet Protocol Router Network (SIPRNET) access for the RAN and RN by the commencement of combat operations proved to be one of the most pressing challenges.

Paul Mitchell summarized with some justification: "network-centric operations in a coalition or alliance environment may ultimately hinge on information releasability rules and the ability to exchange information between networks of different security classifications". ${ }^{34}$ Information sharing problems had hindered previous multinational operations, including the 1991 Gulf War, and the challenges had not been resolved by OIF. ${ }^{35}$ John Kiszely warned in 1999:

We have long recognised the need for maximum interoperability with our allies, and an increasingly important element of this is now the interoperability and compatibility of our IT and, in particular, our Command and Information Systems (CIS). To fail to achieve and maintain such compatibility - both technical and doctrinal - is not only to detract from the overall military capability of a coalition or alliance, but also to detract from the value accorded as a partner, and from the influence which can thereby be wielded. ${ }^{36}$

Intelligence sharing was particularly troublesome during Operation Allied Force in 1999 and problems persisted despite some progress in the wake of that operation. A review of operational level interoperability between the Australian and US militaries lamented in 2004: "There is no institutionalized digital network and associated tactics, techniques, and procedures (TTP) for 
Steven Paget

Forthcoming in Defense \& Security Analysis, 36:1, 2020. This is the post-print version and must not be copied or cited without permission.

the seamless sharing of military operations information and intelligence information between the United States and its allies to support coalition operations." 37

Walter L. Perry and David Kassing put it bluntly in 2015: "The inability to fully share information with coalition partners was a serious obstacle to combined operations. This is a continuing problem that was also manifest in Operation Iraqi Freedom-especially for our closest partners, such as the United Kingdom and Australia." ${ }^{38}$ Each nation operated their own national networks during OIF, including the Australian Defence Secret Network and the British Joint Operational Command System. The US communicated primarily on their national networks - SIPRNET for classified material and the Non-classified Internet Protocol Router Network (NIPRNET) for unclassified material - but neither of those networks could be linked to those of any of the multinational partners. ${ }^{39}$

Both Australia and the UK had obtained “"special' access” to SIPRNET for MIF operations during $\mathrm{OEF} .{ }^{40}$ Various caveats were put in place to prevent the inadvertent exposure of NOFORN (not releasable to foreign nationals) material such as US personnel either inputting or printing material on SIPRNET, before access was removed entirely and the MIO force transitioned to the Coalition Wide Area Network (COWAN) in December 2002. ${ }^{41}$ There were practical concerns such as the absence of compartmentalisation on SIPRNET that meant that there was no way of preventing access to US eyes only material, but President George W. Bush had issued a directive authorising Australian and UK access to SIPRNET. Nevertheless, concerns about access to NOFORN material, which emanated largely from civilian agencies back in the US rather than the military led to access to SIPRNET being cut. As Theo Farrell and Tom Bird have noted: "The connectivity problem is primarily a matter of politics and procedure, not technology." 42 
Steven Paget

Forthcoming in Defense \& Security Analysis, 36:1, 2020. This is the post-print version and must not be copied or cited without permission.

The transition to COWAN required a cultural change as the USN had become accustomed to relying on SIPRNET. While Admiral Robert Natter, dual-hatted as Commanderin-Chief, US Atlantic Fleet and Commander of US Fleet Forces Command, directed that the bulk of material be moved on COWAN and USN personnel worked to ensure that it was being utilised, coalition officers also felt compelled to guarantee that the network was not being bypassed. Jones, in his role as MIF Commander, requested that all USN commanding officers and their staff monitor SIPRNET to ensure that COWAN was not being circumvented. Ships that were bypassing COWAN were directed to move that information over to the network. Some USN sailors also worked on side-by-side terminals to facilitate the population of COWAN. Squadron Leader Sophy Gardner, Royal Air Force, noted that the process of transferring material from SIPRNET to the coalition network "was manual rather than automatic, requiring our US counterparts to find the time (in a high-tempo operational environment) to decide on and implement the transfer of information...these challenges tended to be overcome through face-to-face dialogue and the development of good working relationships, although not without costs to efficiency". ${ }^{43}$

The extent to which COWAN adequately represented the necessary material on SIPRNET has been the source of debate, but some coalition officers felt that there was a gap between the networks as the USN remained inclined to favour their national network. ${ }^{44}$ Context was seen as key when it came to missing information. It was recognized that the USN was "in danger of leaving behind other navies because all of the background and decision-making that goes on over networks like SIPRNET...is lost", which means that other navies "are not in the battle rhythm of the operation". ${ }^{45}$ Trust was an important factor in overcoming technical incompatibilities. While the methods may have been unsophisticated - or "farcical" as Farrell and Bird have described them - ways were found to ensure that Australia and the UK had 
Steven Paget

Forthcoming in Defense \& Security Analysis, 36:1, 2020. This is the post-print version and must not be copied or cited without permission.

access to the necessary information, including US officers reportedly "calling up information on SIPRNET in the presence of British colleagues and then pretending to look the other way". ${ }^{46}$

The inability of Australian vessels to access NATO tactical data links and the limited bandwidth available to coalition ships also created a number of challenges. ${ }^{47}$ Trust was key because when it came to identifying aircraft and establishing a clear air picture, for example, RAN and RN ships were aided by the information provided by the USN's Aegis cruisers. ${ }^{48}$ Technical incompatibilities, realeasbility, and cultural predilections all hindered the ability to share information, but strong personal relationships and the trust that existed between the RAN, RN and USN helped ensure that operations were not compromised. Human and cultural factors, therefore, provided the glue that not only held the multinational force together, but also helped to ensure that the coalition was both efficient and effective.

\section{The Significance of Personal Relationships}

All command structures are at least partly driven by the dynamics of personal relationships to varying degrees. The influence of personalities can be even greater in a coalition setting, where things may well be less rigidly defined than in a national environment. The integration of coalition officers into the command chain and the relatively multifarious force structure necessitated continued and close interaction on the maritime side during OIF. Captain Jones asserted in reference to the necessarily complex command structure: "some of these arrangements, at first glance, can look cumbersome but what is required is for you just to have a lot of good will and good inter-personal relationships". ${ }^{49}$ 
Steven Paget

Forthcoming in Defense \& Security Analysis, 36:1, 2020. This is the post-print version and must not be copied or cited without permission.

If the coalition command structure was personality driven to a degree then Rear Admiral Snelson's position as the coalition deputy ensured that his relationship with Admiral Keating was central to the cohesiveness of the coalition. Snelson was able to share the burden of coalition command responsibilities, allowing Keating to deal with his extensive national commitments. ${ }^{50}$ Keating recalled: "David was fully integrated and it was a significant asset of mine to have a man of his calibre and experience right there in the headquarters, participating in the day-to-day, hour-to-hour, minute-to-minute discussions and decision processes." 51 Furthermore, by focusing on "all things coalition", Costello has exclaimed that Snelson deserves "a great deal of credit for creating harmony among the leaders of the participating countries - a factor critical to the success of the mission".52

The close working relationship established by Keating and Snelson was representative of the coalition as a whole. The development of personal relationships that were generally both positive and productive was the result of a conscious effort. Firstly, the selection of officers for command and liaison positions was planned carefully to ensure that integration within the coalition was achieved with ease and that the conduct of operations would be facilitated by the inclusion of diverse inputs. The collection of LOs from a range of nations at the daily brief numbering anywhere between 12 and 24 at any given time - was considered to be a "remarkable gathering" that consequently produced "a very important and impressive exchange of ideas and initiatives, all of which led to a very efficient and effective utilisation of a wide range of forces". ${ }^{53}$ The willingness and ability to embrace a collective, yet diverse mindset is absolutely essential to integrate effectively into a coalition.

Enduring involvement in the region was the second factor that contributed to the establishment of trusting and effective personal relationships. While traditional ties between nations can aid the process of integration and speed up the development of productive 
Steven Paget

Forthcoming in Defense \& Security Analysis, 36:1, 2020. This is the post-print version and must not be copied or cited without permission.

relationships, the benefit of time should not be underestimated. Costello viewed the encouragement of increased engagement with the RAN and RN as a logical step: "whenever we are together, we go to the appropriate extremes to ensure that we do operate together to cement all of our operational capability... as well as whatever personal relationships you can develop". ${ }^{54}$ The importance of getting to know counterparts, developing trust and engendering confidence was appreciated keenly by the coalition.

The significance of personalities is often overlooked and even when it has been emphasised, it has tended only to draw attention when there has been discord between highprofile individuals. A number of historians have referenced the personality clash between General Douglas MacArthur and Admiral Thomas Hart during the Second World War, while David Horner has noted pertinently that the "adversarial relationship" between MacArthur and his Australian subordinate, General Sir Thomas Blamey, spoke to the "problems of coalition warfare". ${ }^{55}$ It is important, however, to emphasise the benefits of successful personal relationships. Keating professed: "the trust, the friendship, the camaraderie, the professional respect, appreciation for background, all of those combined to a very collegial and yet professional...atmosphere in the headquarters". ${ }^{56}$

The value of human interoperability cannot be adequately encapsulated in any form of standardisation agreement, but its intangibility should not cloud its significance. Captain Nick Lambert (RN), Snelson's Chief of Staff, summarised: “A combination of liaison officers and personal relationships overcame geographical dislocation and an unwieldy command structure. ${ }^{\circ 57}$ The significant overmatch meant that the coalition's success did not hinge on personal relationships, but the cohesiveness achieved contributed to the effectiveness of naval operations during OIF. While personalities sometimes mesh naturally, leading to the prompt enactment of productive working relationships, it is prudent for personal connections to be 
Steven Paget

Forthcoming in Defense \& Security Analysis, 36:1, 2020. This is the post-print version and must not be copied or cited without permission.

cultivated at every opportunity. The conduct of multinational exercises, the regular exchange of personnel and the early deployment of LOs can facilitate the development of cooperative and effective relationships within a coalition as demonstrated during OIF.

\section{Multinational Exercises: Practice Makes Perfect}

The well-known dictum "train hard, fight easy", which has proven true irrespective of the nation or service involved, takes on increased significance when it is applied to the multinational environment. Michael Smith observed: "Training, is the 'center of gravity' for successful coalition operations. ${ }^{n 8}$ Responsibility for training military forces will remain a national obligation primarily, but once the requisite competency has been achieved, forces will need to participate in multinational exercises in preparation for the likelihood of engaging in coalition operations.

Exercises are vital for testing and improving interoperability in a range of areas, including command and control, communications, doctrine, intelligence, logistics and tactics, techniques and procedures (TTP). In the same vein that the Iguana Voladora/Flying Iguana annual multinational parachute exercise conducted by countries from the Americas is said to create a culture of "Brothers of Silk", naval exercises help to acclimatise personnel to diverse operating styles, resolve historical differences and create enduring relationships. ${ }^{59}$ Exercises are important equally for revealing problems and discovering challenges in the quest to enact interoperability. Discrepancies in training levels between national forces can be a challenging "point of friction" and it is important that any potentially inhibiting factors are addressed prior to the deployment of forces for operations. ${ }^{60}$ There is always scope to further improve the level of interoperability achieved, even amongst the closest partners such as the RAN, RN and USN. 
Steven Paget

Forthcoming in Defense \& Security Analysis, 36:1, 2020. This is the post-print version and must not be copied or cited without permission.

Colonel Eric Larson, US Army, has warned: "Even when you believe you are interoperable, you will find break points." 61

Although interoperability between naval forces is regarded as easier to achieve than amongst other services, the regular conduct of exercises is central to facilitating the ability of navies to integrate quickly and cooperate effectively, with the level of commitment to training and exercises being commensurate with the ability to interoperate. ${ }^{62}$ The USN, for example, participates - albeit to differing levels of commitment - in hundreds of bilateral and multinational exercises each year. ${ }^{63}$ In an era of austerity, nations need to balance fiscal limitations with the practical requirement to enhance interoperability. While nations will need to engage with a broad range of countries for military and political reasons especially, multinational exercises with more likely coalition partners will remain of enduring importance. To that point, Mark Lawrence has proposed: "How sustained and exhaustive any demonstration of deep interoperability is will ultimately determine whether a given partner should be prioritized for enhanced cooperation at sea." 64 It was noted in 2014 that: "the US Defense Department has also begun to multilateralise most if not all of its existing exercise programmes in Europe and to conduct more events with the more capable allies and fewer events with the less capable allies". ${ }^{65}$

The long-term commitment to multinational exercises and training paid "significant dividends" during OIF. ${ }^{66}$ The level of familiarity amongst the RAN, RN and USN, which was the bedrock of effective cooperation, was achieved partly through the conduct of bi-national and multinational training. The involvement of partners who were less familiar to the RAN, RN and USN underlined the merits of sustained interaction. Commodore Peterson outlined that when it came to less traditional partners: "It was difficult for us to meaningfully mutually support each other...and it has nothing to do with the quality of the mariners...we just didn't 
Steven Paget

Forthcoming in Defense \& Security Analysis, 36:1, 2020. This is the post-print version and must not be copied or cited without permission.

know each other well enough to do things." ${ }^{67}$ The interaction amongst the RAN, RN and USN has surpassed the level of engagement with many other navies, leading to noticeable benefits for interoperability. ${ }^{68}$

NATO has played an important role in facilitating interoperability between the $\mathrm{RN}$ and USN. A range of Allied Tactical Publications (ATPs) and standardisation agreements (STANAGs) provide the foundation of interoperability, which is then tested and improved through the conduct of multinational exercises. NATO's reach transcends the organisation as other navies use earlier versions of its publications to underpin their own. The work of the Multinational Interoperability Council, which counts Australia, Canada, France, Germany, the UK and the US amongst its members, has developed a number of NATO approved Experimental Tactics (EXTACs), STANAGs and ATPs. ${ }^{69}$ NATO exercises, both during and after the Cold War, addressed the full spectrum of naval operations. ${ }^{70}$ These exercises aided cooperation between the RN and the USN, but the benefits of NATO have stretched far beyond the members of the organisation due to the cross-pollination of naval forces, which has led to its "doctrine and procedures" becoming "almost the common currency in multinational maritime operations". ${ }^{71}$ Eric Lehre has deduced: "some 60 years of NATO procedural interoperability has engendered a cultural interoperability of unstated but no less strong mutual understanding that guides how one does business during coalition warfare". ${ }^{72}$

NATO has not been the only avenue for cooperation. The biennial US-led and planned Rim of the Pacific (RIMPAC) Exercise has provided the USN and the RAN with the chance to cooperate with a range of nations during realistic scenarios. The RN's inaugural involvement in RIMPAC in 1986 - the first time that a nation outside of the Pacific Rim had participated also created another opportunity for interaction with the RAN and USN. ${ }^{73}$ The conduct of a range of other bilateral and multinational exercises, moreover, including Talisman Saber and 
Steven Paget

Forthcoming in Defense \& Security Analysis, 36:1, 2020. This is the post-print version and must not be copied or cited without permission.

Five Power Defence Arrangements (FPDA) initiatives, have also helped to further the enactment of interoperability. Captain Peter Lockwood (RAN), Commanding Officer of HMAS Anzac, was convinced that the experience of exercising with the USN and; albeit less frequently with the RN, helped to facilitate effective coordination in the Persian Gulf. ${ }^{74}$ In noting that exercises are often viewed as "the lifeblood of interoperability", a review of operational level interoperability between the armed forces of Australia and the US affirmed: "exercises give the relationship added meaning between periods of conflict, and prepare the partnership for conflict by validating TTP and testing new approaches". ${ }^{75}$ Jeffrey Barlow, in assessing OEF, has attributed the level of cohesion achieved to the long history of multinational exercises, noting that the sailors "knew how to broker among themselves the informal means of cooperation that enabled their forces to overcome the rigidities imposed by differing national conceptions". ${ }^{76}$ Robert Rubel argued similarly that in the case of the global maritime partnership after 2001: "Information sharing, lubricated by trust and confidence built through routine and repeated peacetime engagement, was key to its effectiveness."77

Operations in the Persian Gulf have, from an interoperability perspective, provided the RAN, RN and USN with extended opportunities to work together and hone skills. Peterson pointed out that throughout much of the 1990s and early 2000s, the RAN, RN and USN, "haven't done anything but operate together", but he warned that the experience of regular interaction and operations should not be taken for granted:

I think for future operations, you would really have to get conscious thought and effort to doing a whole lot more practice, training, exchanges and literally flying people from country-to-country, I think, in order to do this...even with the best coordinated procedures, you just can't drop in and do it overnight and it really makes bi-lateral and multilateral exercises all the more important... ${ }^{78}$

The operational tempo over the last two decades has, in truth, ensured that "doing" has superseded "practicing", but it has not diminished the importance of obtaining experience 
Steven Paget

Forthcoming in Defense \& Security Analysis, 36:1, 2020. This is the post-print version and must not be copied or cited without permission.

alongside coalition partners during exercises. The extensive operational experience reinforced and strengthened the pre-existing working relationship between the navies rather than created it.

The coordination of observation was one of the key aspects of interoperability when it came to naval gunfire support (NGS) for the assault on the Al Faw Peninsula on 20 March 2003. While observation was conducted solely by the British, it did not pose any problems for Anzac, in part because of common and collective training. ${ }^{79}$ In addition to the reassurance provided by gunnery control and observation post training, 148 (Meiktila) Commando Forward Observation Battery, Royal Artillery, the unit responsible for providing observation for NGS, had extensive experience of participating in multinational exercises, including those involving RAN and USN ships. The Joint Warrior Exercises conducted off Cape Wrath twice a year had provided 148 Battery with the opportunity to work with both NATO and non-NATO ships. Aside from working with USN ships at Cape Wrath, 148 Battery had participated in a range of overseas exercises, including in the US alongside the Air Naval Gunfire Liaison Company (ANGLICO) and FPDA exercises involving RAN ships. ${ }^{80}$ Not only were 148 Battery personnel comfortable working with Anzac, but they were also more than capable of spotting for USN ships, if they had provided NGS.

RAN involvement in multinational exercises and knowledge of NATO procedures meant that the integration of Anzac was achieved with relative ease. Captain Lockwood confirmed that the crew of Anzac was "very familiar" with observation procedures. ${ }^{81}$ Although Australia is not a NATO member, the RAN were acquainted with ATP-4, which governed spotting procedures, meaning that they were capable of working with observers from a wide range of nations. Brigadier Jim Dutton, the Commander of 3 Commando Brigade, Royal Marines, was confident about Australian inclusion in the NGS mission because of the "shared 
Steven Paget

Forthcoming in Defense \& Security Analysis, 36:1, 2020. This is the post-print version and must not be copied or cited without permission.

understanding" and "shared training" between the RAN and $\mathrm{RN} .{ }^{82}$ While it is hard to quantify the extent to which previous interaction aided the assault on the Al Faw peninsula, there can be no doubt that it was advantageous.

The importance of perceptive interoperability was also demonstrated during the conduct of boarding operations. In noting that it was necessary to "develop a synergy - an effect greater than the sum of the units involved," Jones outlined that it was vital for the MIF to adopt "a much more interchangeable approach between coalition ships, helicopters, boats and boarding parties". ${ }^{83}$ Participants in the MIF were required to work closely with their multinational partners and integrate as effectively as possible. The importance of learning from counterparts and accommodating new approaches was demonstrated during the arrival of ships in theatre. Anzac, for example, received briefings from the commanding officers and operations teams of RN and USN ships on arrival and, initially, conducted boardings under the wing of other ships until they were accustomed to the approach being operated in theatre. ${ }^{84}$ Equally, once the Australian ship had generated a sufficient level of experience, USN boarding teams later went on board Anzac to align and hone procedures, which served to increase the surge capacity of the MIF. ${ }^{85}$ The MIF operated a policy of adopting the best ideas, and, input from each of the participating nations was used to shape the conduct of operations.

It was understood that completely interchangeable boarding parties that could operate from different ships were required. In the lead up to the commencement of the conflict, 130 sailors, consisting of boarding parties and supporting personnel, were moved to HMAS Kanimbla, including teams from USN ships that were being moved further down the Gulf. The conglomerate multinational RHIB effort was responsible for the provision of around-the-clock coverage of the mouth of the Khawr Abd Allah water-way. ${ }^{86}$ Jones reflected: "The smooth integration of these teams and their refinement of boat recognition procedures to prevent 
Steven Paget

Forthcoming in Defense \& Security Analysis, 36:1, 2020. This is the post-print version and must not be copied or cited without permission.

fratricide reflected highly on all involved." ${ }^{87}$ Not only did boarding parties prove to be interchangeable, but it was noted during Australian command of the MIF that ships "frequently remarked how much they appreciated the less rigid levels of control...by comparison with their usual experience". ${ }^{88}$ The willingness of the USN's leadership to accept a more relaxed approach was a reflection of the trust placed in their multinational partners based on mutual understanding generated through experience.

Far from breeding contempt, familiarity in the multinational military environment laid the foundation for success in the Persian Gulf. Training and exercises were, nevertheless, just one means of ensuring smooth and rapid integration, with a number of smaller scale measures being utilised to avoid a cold start for the coalition.

\section{Personnel Exchanges: An Invaluable Initiative}

The emergence of a common understanding does not occur through a process of osmosis. It can be developed by a number of factors such as a shared lineage and collective experience. One traditional means of ensuring that the linkages between nations are cultivated and preserved is the conduct of personnel exchanges, which can be continued - even if on a smaller scale - during times of austerity. Personnel exchanges, as well as fostering trust, provide a window into the culture and workings of a foreign military. Long-standing exchanges amongst core allies such as Australia, the UK and the US, as well as newer relationships with less traditional partner nations, can create enduring links that help to smooth integration during the conduct of multinational operations. Numerous nations pursue exchange programmes, but the ones conducted by Australia, the UK and the US are extensive and diverse in nature.

The Personnel Exchange Program (PEP) conducted by the US is intended to "foster a mutually beneficial exchange of experiences, professional knowledge, and doctrine to the 
Steven Paget

Forthcoming in Defense \& Security Analysis, 36:1, 2020. This is the post-print version and must not be copied or cited without permission.

maximum extent possible within existing policies". ${ }^{89}$ Personnel are generally exchanged for a two-year period in order to achieve that goal, during which time they serve as completely integrated members of their host organisation. The USN conducts 208 exchanges with 20 foreign nations, including traditional partners such as Australia, Canada and the UK. ${ }^{90}$ The experience of 10 USN submariners on exchange with the RAN in 2014 as part of a programme that has existed since the 1970s, prompted Lieutenant Commander Travis Zettel (USN), the officer in charge of the American detachment, to declare: "The exchange program is an excellent opportunity to progress the interoperability of both navies". ${ }^{91}$ As well as the obvious benefits for the individual officers, the exchanges help to foster good will and, more importantly, generate a level of experience of - and confidence in - the operating culture of allies within the respective service. A cadre of personnel with experience in a foreign service can provide disproportionate benefits due to their capacity to share knowledge about the culture and doctrine of a coalition partner.

There were a number of notable examples of the coalition benefitting from the multinational experience harboured by several prominent individuals during operations in the Persian Gulf between the commencement of OEF and OIF. Captain James Goldrick (RAN), for example, served as the Commander of the MIF for a spell in 2002. Goldrick had qualified as a seaman officer on loan to the $\mathrm{RN}$ and after undertaking principal warfare officer training with the RN, spent two years on exchange with the British on board HMS Liverpool. This extended working knowledge of RN TTP, as well operating culture, was in Goldrick's own words: "very important". While his experience of operating with the USN was not as extensive, in addition to spending time as a research scholar at the US Naval War College (USNWC), Goldrick had undertaken a coalition operations job, working for the officer who was effectively the theatre commander, on board USS Coronado during the 1998 RIMPAC exercise. This 
Steven Paget

Forthcoming in Defense \& Security Analysis, 36:1, 2020. This is the post-print version and must not be copied or cited without permission.

short-term exposure to the USN was "vital" in obtaining an understanding of how the USN operated. The combined experience of operating with the RN and USN ensured that Goldrick was, ultimately, "pretty comfortable" in leading the task force soon after his arrival in theatre. ${ }^{92}$ Similar benefits were experienced by those operators conducting phase three operations.

The benefits of personnel exchanges appeared to be particularly prevalent amongst RAN and RN officers. Captain Mark Anderson (RN), HMS Marlborough's Commanding Officer, opined: "we speak the same language, we've often trained in the same establishments, many Australians and Brits have done exchange tours. It's not a challenge [for the RAN and RN to integrate]. ${ }^{\circ 3}$ Similar views permeated the highest levels of RAN and RN leadership in theatre. Rear Admiral Snelson's period on exchange with the RAN, which saw him join HMAS Derwent in 1980, afforded him both a working knowledge of the Australian service, as well as direct contact with many of his future counterparts. That experience was obviously of great value to the individual officer, but it also ensured that the Australians felt that Snelson's likemindedness made him an ideal advocate for the RAN. Captain Jones recalled that when he was unable to attend a planning meeting on board HMS Ocean prior to the assault on the Al Faw Peninsula due to his responsibilities with the MIF, he was "very comfortable" with Admiral Snelson representing both the UK and Australian perspectives due to their prior acquaintance and discussions in theatre. ${ }^{94}$ Jones had, furthermore, completed his Principal Warfare Officer course in the UK, which helped ensure that he was familiar and comfortable working alongside the RN. ${ }^{95}$

Commander Spedding, an RAN LO based with US Central Command (CENTCOM), acknowledged of the Australians: "many of us in more senior positions had worked with the Brits before". One intrinsic benefit was that prior knowledge of international counterparts meant that individuals did not need to "build up trust from an unknown position". ${ }^{96}$ OIF 
Steven Paget

Forthcoming in Defense \& Security Analysis, 36:1, 2020. This is the post-print version and must not be copied or cited without permission.

indicated that long-term familiarity can mitigate, to a degree, the drawbacks of short-term separation. Snelson summarised in reference to the RAN and RN:

the two navies just clicked back together again. They now look really rather different, their ships are different, we wear different sorts of uniforms, job titles are different and the Australian navy in many senses is closer to the American navy in the way it looks...but there was something about the thinking and shared heritage. ${ }^{97}$

The already strong bonds that existed between many of the officers laid the foundation for the close cooperation that was enacted amongst the coalition. While the prevalence of traditional exchanges between the RAN and RN created a platform for collaboration amongst those two navies, the coalition reaped the benefits of a much broader exchange programme. The completion of PME programmes in other nations has helped to foster perceptive interoperability during recent operations, including OIF. Participation in overseas PME can help to facilitate pre-existing bonds, develop understanding and trust and offer a window into the culture and practices of a foreign military. ${ }^{98}$ Lockwood, for example, found the process of integrating with the USN somewhat easier having completed the staff course at USNWC. ${ }^{99}$ Pre-existing interaction with peers over an extended time period provided an awareness of the culture and practices of the USN.

Perhaps the biggest testament to the significance of personnel exchanges is the very real concern shared by those officers who have had the opportunity to experience them that such arrangements are on the wane. One RN officer expressed that the reduction of exchanges with principal partners such as the RAN and USN is a major worry:

I think that's to the detriment of interoperability and I think it's a shame. Now, I can understand why and the financial factors and all of the other points but I think if we want to be able to operate worldwide in coalitions...then an understanding of how each other works, the limitations they're under, their procedures and also cultures and all that sort of thing is fundamental to working efficiently together... ${ }^{100}$ 
Steven Paget

Forthcoming in Defense \& Security Analysis, 36:1, 2020. This is the post-print version and must not be copied or cited without permission.

Practical realities have ensured that traditional ties are no longer sufficient to ensure that a common understanding exists between geographically distant nations.

Many of the senior officers, commanding officers and LOs that represented the RAN, RN and USN during OIF knew their counterparts and maintained friendships that were developed through exchange stints and shared professional military education. While LOs are small in number, their reach and influence provide far-reaching benefits that outweigh their cost - both in economic and manpower terms. Perceptive interoperability is an amorphous concept that is continually shifting and, consequently, relationships need to be refreshed and enriched constantly.

\section{Liaison Officers: The Essential Bridge}

LOs serve as important conduits between the various forces involved during the conduct of multinational exercises and operations. A 2008 NATO technical report noted that LOs are "conversant in the national language and culture of the forces involved, can smooth out communication problems, and may enhance coordination and cooperation". ${ }^{101}$ LOs have been and, in many ways, continue to be the keystone of interoperability during multinational operations.

LOs have been essential, historically, in helping to mitigate points of contention between multinational forces and in clarifying the intent of commanders. Technological advancements, especially the development of network-centric warfare, have compounded the need for liaison rather than eradicating the utility of LOs. Whilst internet protocol communications have increased the speed with which messages can be relayed, the medium is not without its complications. Aspects of non-verbal communications such as tone of voice and facial expressions, which can be illustrative in conveying intent, are not factors. Although not 
Steven Paget

Forthcoming in Defense \& Security Analysis, 36:1, 2020. This is the post-print version and must not be copied or cited without permission.

a foregone conclusion, there is an increased risk of misunderstanding and even contention. "Digitised" liaison teams may also be necessary to help facilitate the technological link-up between multinational partners, especially when there is a gulf in national technologies. ${ }^{102}$ The widespread and early deployment of LOs at the operational and tactical levels is, ultimately, crucial to the achievement of unity and the reduction of friction during multinational operations.

The naval coalition during OIF was underpinned by an extensive liaison network. The RN assigned LOs to all afloat American task groups, while the RAN deployed LOs widely, including to CTF 55, COMDESRON 50, the Kuwaiti/Emirati/Bahraini Defence of Kuwait task group), USS Chinook (a USN patrol vessel), the Polish support ship ORP Kontradmirał Xawery Czernicki and the Royal Marines. ${ }^{103}$ The navies also deployed liaison officers to US CENTCOM and Fifth Fleet Headquarters in Bahrain. The widespread deployment of LOs for operations in the Persian Gulf was, to Burnell-Nugent, "all part of the game of keeping a coalition staff hanging together". ${ }^{104}$ LOs were essential sources of knowledge for their hosts, but they were also recipients of vital information, which helped to keep their parent organisation in the loop. Captain Jones concluded, on the basis of evidence from the RAN's experience during the Gulf War, "if you could put a liaison officer in all the key points, that's where you needed to be". ${ }^{105}$ Quality was just as important as quantity. Costello adjudged: "By sending superstars you lose talented players from your ship and their current job, but the return on investment is huge because these people act as your personal liaison to the leadership of the receiving command and provide timely feedback as to what is going on in that headquarters and how you can maximize your effectiveness."106

LOs were privy to goings-on within their host service/organisation and they were able to gauge moods and sentiments that may not have been apparent in written or verbal orders. 
Steven Paget

Forthcoming in Defense \& Security Analysis, 36:1, 2020. This is the post-print version and must not be copied or cited without permission.

LOs also provided essential linkages when slight differences in operating cultures became apparent between the coalition partners. Commander Steve Aiken, an RN planner that was embedded with Fifth Fleet, acknowledged: "LOs, who are in the mindset of their parent organisations and who can assimilate with their host groups are essential. They have to understand the nuances and must be free to convey those thoughts through both chains of command." ${ }^{107}$ It was accepted that despite the extensive experience of operating together in the Persian Gulf, the deployment of LOs in the lead-up to conflict added value as they helped to open minds and provided an alternative way of thinking, which was extremely valuable in a collaborative environment. ${ }^{108}$ The provision of NGS, which required some persuasion by Australian and British officers to obtain approval, was a clear example of diversity in the planning process, as the Americans had forecast that air power could provide sufficient support for the assault on the Al Faw peninsula. ${ }^{109}$

LOs were also crucial in either preventing or nullifying misunderstandings between coalition partners. Peterson, in assessing the value of LOs, stated: "Without that kind of close communication, I think we would have had more animosities, more mis-signals, more misunderstanding and more missed opportunities." 110 The capacity to discuss issues face-toface and look counterparts in the eye helped to foster confidence and build credibility. Commander Peter Leavy (RAN), who served as Captain Jones' Chief of Staff, observed of LOs: “they're very important, even amongst long-standing partners like Britain, Australia and the US. We've all worked together for a long period of time and we do understand each other quite well, but there are subtle differences that can inadvertently cause issues. I think it's important having those liaison positions and having them established early". ${ }^{111}$

The importance of LOs was just as great, if not greater, when non-native English speaking nations were involved, as was the case with the Kuwaiti Navy. The RAN had a strong 
Steven Paget

Forthcoming in Defense \& Security Analysis, 36:1, 2020. This is the post-print version and must not be copied or cited without permission.

connection with the Kuwaiti Navy and, particularly, General Ahmad Al Mulla, Chief of the Kuwaiti Navy, as well as Major Majeed Al Shameri, the LO deployed with the Australians. Many of the Kuwaiti officers had prior knowledge of Australia through initiatives such as exchanges, professional military education and visits. Major Al Shameri turned out to be a crucial LO for the RAN as his ability to speak Arabic was essential in communicating with prisoners and deciphering captured documents. This was particularly important when it came to mapping out the location of mines and the Major's sterling work resulted in him being awarded a Maritime Commander Australia Commendation. ${ }^{112}$

LOs have played an invaluable role in enacting coordination during coalition operations and OIF proved to be no exception, despite ongoing progress in improving interoperability. Costello viewed LOs as a "bridge" between the navies and concluded:

In my opinion, you cannot possibly have too many liaison officers, or too many exchange officers because they provide huge value, both from a specific war-fighting perspective, as well as a cultural perspective and those are significant issues that can help or hurt you... ${ }^{113}$

While extensive preparatory efforts are essential in laying the groundwork for interoperability, the results are not infallible. As with any modelling process, the measures implemented to enhance interoperability have left some rough edges that LOs help to smooth out. LOs often serve as the final piece in the interoperability jigsaw by mitigating or resolving points of difference.

\section{Conclusion: Relationships are Key}

Commodore Rob Kramer, Royal Netherlands Navy, emphasised: "Interoperability...always has a couple of aspects...The first aspect is the equipment side of things...But another very important aspect of interoperability is the cultural side. We have got to invest in friendship; 
Steven Paget

Forthcoming in Defense \& Security Analysis, 36:1, 2020. This is the post-print version and must not be copied or cited without permission.

we've got to know each other personally."114 The necessity of participating in multinational operations has been a forcing function for navies to address the issue of interoperability. While navies have traditionally been considered the most interoperable of all of the services, differences do still exist amongst even the closest allies. Much work has been done in a range of areas such as doctrine and equipment and while the level of interoperability achieved by the RAN, RN and USN is impressive, it must not be taken for granted.

The naval coalition during OIF was both efficient and effective. That accomplishment was a reflection, in part, of the long-standing partnerships between the navies and their enduring involvement in the region. It was also testament to the quality of the mariners and the competency of the individual navies. The icing on the cake - both in terms of capping the performance and holding the mix together - was the trust and understanding that was developed through multinational exercises, personnel exchanges and LOs. High levels of interoperability at the tactical, operational and technical levels were cemented by the achievement of advanced perceptive interoperability.

Coalition operations can be viewed through the metaphor of a belt and pulley system. While standardisation in areas such as equipment and TTP represent the cogs, perceptive interoperability is the belt that drives the system. That is especially true in diverse and less cohesive coalitions, but it is also a reality amongst long-standing partners such as the RAN, RN and USN, which was borne out during OIF. There are many commonalities and some nearidentical features, but none of the navies are a mirror image of each other. The capacity to perceive and mitigate these differences, albeit minor in some cases, enhances the cohesiveness of the navies and helps to elevate them to a level of interoperability that surpasses the relationship between most other navies. 
Steven Paget

Forthcoming in Defense \& Security Analysis, 36:1, 2020. This is the post-print version and must not be copied or cited without permission.

Aside from the relevance for the relationship amongst the RAN, RN and USN, the development of perceptive interoperability provides important portents that are applicable to not only all navies, but the armed forces of all nations. The enhancement of perceptive interoperability is an ongoing endeavour that requires significant investments of time, money and effort. Personal relationships need to be cultivated and different ways of doing business need to be understood, as well as respected. Platforms and personnel come and go, but the relationships are enduring, which means that continual interaction is required to enrich them. Where the cultural connections between armed forces are more disparate, even greater engagement will be necessary to break down walls and build bridges between personnel. Investments in peacetime engagement can be seen as paying the premium on an insurance policy, with the benefits being realised during the conduct of operations. As the prevalence of multinational operations continues to increase, respect, trust and understanding must be cultivated between likely coalition partners to engender increases in efficiency and effectiveness.

\footnotetext{
${ }^{1}$ Benjamin Sakrisson, 'RIMPAC Air Commander: "Relationships Are Key to Interoperability"', 21 July 2014, <http://www.pacom.mil/Media/News/Article/564376/rimpac-air-commander-relationships-are-key-tointeroperability/> (accessed 2 May 2018).

${ }^{2}$ Olivier Schmitt, 'More Allies, Weaker Missions? How Junior Partners Contribute to Multinational Military Operations', Contemporary Security Policy, (2018), p.4.

${ }^{3}$ Thomas Crowson, 'Breaking it Down Barney Style: A Framework for Cultural Interoperability', Canadian Foreign Policy Journal, 22:2 (2016), p.109.

${ }^{4}$ Major General Duane A. Gamble and Colonel Michelle M.T. Letcher, 'The Three Dimensions of Interoperability for Multinational Training at the JMRC', 6 September 2016,

<https://www.army.mil/article/173432/the_three_dimensions_of_interoperability_for_multinational_training_at _the_jmrc > (accessed 2 May 2018).

${ }^{5}$ While some refer to "transactional interoperability" to address behavioural, ethical and cultural factors, others have furthered the notion of "behavioural interoperability" to encapsulate the influence of strategy, doctrine, constitutions, legal systems and customs. Terry Moon, Suzanne Fewell and Hayley Reynolds, 'The What, Why, When and How of Interoperability', Defense \& Security Analysis, 24:1 (March 2008), p.5; Michael Codner, 'Hanging Together: Interoperability Within the Alliance and with Coalition Partners in an Era of Technological Innovation', NATO Research Fellowship Report (June 1999), p.3.

${ }^{6}$ Angela Febbraro, Brian McKee and Sharon Riedel, 'Multinational Military Operations and Intercultural Factors', NATO RTO Technical Report, TR-HFM-120 (Neuilly-sur-Seine Cedex, November 2008), p.1-3.

${ }^{7}$ It is worth noting that the conflict was given different names by each of the coalition nations. It was designated Operation Iraqi Freedom by the US, Operation Telic by the UK and Operation Falconer by Australia.
} 
Steven Paget

Forthcoming in Defense \& Security Analysis, 36:1, 2020. This is the post-print version and must not be copied or cited without permission.

${ }^{8}$ NATO, 'Interoperability: Connecting NATO Forces', 6 June 2017,
<https://www.nato.int/cps/em/natohq/topics_84112.htm> (accessed 19 February 2019).
${ }^{9}$ Basil Germond, 'Multinational Military Cooperation and its Challenges: The Case of European Naval Operations
in the Wider Mediterranean Area', International Relations, 22:173 (2008), pp.174-175.
${ }^{10}$ Chad Foster, 'Readiness and Interoperability in Operation Atlantic Resolve', Military Review (January-
February 2018), p.96.
${ }^{11}$ Efrat Elron, Boas Shamir and Eyal Ben-Ari, 'Why Don't They Fight Each Other? Cultural Diversity and Operational Unity in Multinational Forces', Armed Forces \& Society, $26: 73$ (1999), p.81.

${ }^{12}$ Robert A. Rubinstein, Diana M. Keller and Michael E. Scherger, 'Culture and Interoperability in Integrated Missions', International Peacekeeping, 15:4 (August 2008), p.540.

${ }^{13}$ Alejandro P. Briceno, 'The Use of Cultural Studies in Military Operations: A Model for Assessing ValuesBased Differences', in Paula Holmes-Eber, Patrice M. Scanlon and Andrea L. Hamlem (eds.), Applications in Operational Culture: Perspectives from the Field (Quantico: Marine Corps University, 2009), p.35.

${ }^{14}$ Elron, Shamir and Ben-Ari, 'Why Don’t They Fight Each Other?', pp.88-89.

${ }^{15}$ Joseph Soeters and Tibor Szvircsev Tresch, 'Towards Cultural Integration in Multinational Peace Operations', Defence Studies, 10:1-2 (March-June 2010), pp.278-279.

${ }^{16}$ Ibid., p.281.

${ }^{17}$ Joseph L. Soeters, Cristina-Rodica Poponete and Joseph T. Page Jr., 'Culture's Consequences in the Military', in Thomas W. Britt, Amy B. Adler and Carl Andrew Castro (eds.), The Psychology of Serving in Peace and Combat Military Culture, Volume 4: Military Culture (Westport: Praeger, 2006), pp.26-27.

${ }^{18}$ Joseph Soeters and Miepke Bos-Bakx, 'Cross-Cultural Issues in Peacekeeping Operations', in Thomas W. Britt and Amy B. Adler (eds.), The Psychology of the Peacekeeper: Lessons from the Field (Westport: Praeger, 2003), p.288, p.291.

${ }^{19}$ Soeters and Tresch, 'Towards Cultural Integration in Multinational Peace Operations', p.278.

20 Tibor Szircsev Tresch, 'Cultural and Political Challenges in Military Missions: How Officers View Multiculturality in Armed Forces', in Giuseppe Caforio (ed.), Advances in Military Sociology: Essays in Honor of Charles C. Moskos, Part A (Bingley: Emerald, 2009), p.116; René Moelker, Joseph Soeters and Ulrich vom Hagen, 'Sympathy, the Cement of Interoperability: Findings on Ten Years of German-Netherlands Military Cooperation', Armed Forces \& Society, 33:4 (2007), p.497.

${ }^{21}$ Briceno, 'The Use of Cultural Studies in Military Operations', p.36.

${ }^{22}$ Angela R Febbraro, 'Leadership and Management Teams in Multinational Military Cooperation', in Joseph Soeters and Philippe Manigart (eds.), Military Cooperation in Multinational Peace Operations: Managing Cultural Diversity and Crisis Response (Abingdon: Routledge, 2008), p.68.

${ }^{23}$ Monty Khanna, 'Training Together - A Fundamental Building Block for Pulling Together', Maritime Affairs: Journal of the National Maritime Foundation of India, 11:2 (Winter 2015), p.114.

${ }^{24}$ John B. Hattendorf, 'Foreword', in Bruce A. Elleman and S.C.M. Paine (eds.), Naval Coalition Warfare: From the Napoleonic War to Operation Iraqi Freedom (Oxford: Routledge, 2008), p.xvi.

${ }^{25}$ Jon Whitford and Thomas-Durell Young have asserted: 'Ships and aircraft...can be thought of as integral platforms of weapons and capabilities which can be delegated in their entirety to non-national commanders to carry out specified tasks.' Important issues such as command authorities and logistics make the integration of land forces more challenging. Jon Whitford and Thomas-Durell Young, 'Multinational Command Authorities: The Need for Change in NATO', Defense Analysis, 13:1 (1997), p.39. For more on command authorities, see: ThomasDurell Young, 'The Revolution in Military Affairs and Coalition Operations: Problem Areas and Solutions', Defense \& Security Analysis, 19:2 (2003), pp.111-130.

26 Germond, 'Multinational Military Cooperation and its Challenges', p.175; Roger Palin, 'The Military Dimension: Specific Aspects', The Adelphi Papers, 35:294 (1995), p.52.

${ }^{27}$ Basil Germond, The Maritime Dimension of European Security: Seapower and the European Union (Basingstoke: Palgrave Macmillan, 2015), p.33.

${ }^{28}$ Tim Ripley and Richard Scott, 'Strike, Protect, Sustain', Jane's Defence Weekly, 26 March 2003.

${ }^{29}$ Mark McIntosh, 'Reflections on Persian Gulf Naval Operations', Australian Defence Force Journal, Issue No.184 (2011), p.69; Lieutenant Commander Peter Arnold, RAN, interview with author, 1 September 2011. The ranks used in the body of the text are those held by participants at the time of operations, whereas those listed in the endnotes relate to those held at the date of the interview. As a result, there are some discrepancies between ranks in the endnotes and the body of the text.

${ }^{30}$ Benjamin Lambeth, Combat Pair: The Evolution of Air-Navy Integration in Strike Warfare (Santa Monica: RAND, 2007), p.61. 
Steven Paget

Forthcoming in Defense \& Security Analysis, 36:1, 2020. This is the post-print version and must not be copied or cited without permission.

${ }^{31}$ The NAG Commander role entailed command of between 17 and 34 ships at any given period between February and June 2003. Peter Jones, 'Task Group Command, 1990-2003', in John Mortimer and David Stevens (eds.), Presence, Power Projection and Sea Control: The RAN in the Gulf, 1990-2009 (Canberra: Sea Power CentreAustralia, 2009), p.80; Captain John Peterson, USN, first interview with author, 30 August 2011.

32 Barry Costello, Fortune Favors Boldness: The Story of Naval Valor During Operation Iraqi Freedom (Jacksonville: Fortis, 2019), p.306.

${ }^{33}$ The wider dynamics of RAN, RN and USN relations are examined in Steven Paget, The Dynamics of Coalition Naval Warfare: The Special Relationship at Sea (Abingdon: Routledge, 2017).

${ }^{34}$ Paul T. Mitchell, 'Small Navies and Network-Centric Warfare: Is there a Role?', Naval War College Review, LVI: 2 (Spring 2003), p.89.

${ }^{35}$ Glen Segell, 'Information Sharing at United States Central Command', in Irina Goldenberg, Joseph Soeters, and Waylon H. Dean (eds.), Information Sharing in Military Operations (Cham: Springer, 2017), p.107.

${ }^{36}$ John Kiszely, 'Achieving High Tempo New Challenges', The RUSI Journal, 144:6 (1999), pp.48-49.

${ }^{37}$ Combined Review Team, Review of Operational Level Interoperability Between the Military Forces of

Australia and the United States of America (Canberra: Department of Defence, October 2002), p.8.

${ }^{38}$ Walter L. Perry and David Kassing, Toppling the Taliban: Air-Ground Operations in Afghanistan, October 2001-June 2002 (Santa Monia: RAND, 2015), p.36.

${ }^{39}$ Martin M. Westphal and Thomas C. Lang, 'Conducting Operations in a Mission Partner Environment', JFQ, 74 (3rd Quarter 2014), p.47.

${ }^{40}$ Adam D. M. Svendsen, 'The Globalization of Intelligence Since 9/11: The Optimization of Intelligence

Liaison Arrangements', International Journal of Intelligence and CounterIntelligence, 21:4 (2008), p.664.

${ }^{41}$ Paget, The Dynamics of Coalition Naval Warfare, pp.207-209.

${ }^{42}$ Theo Farrell and Tim Bird, 'Innovating within Cost and Cultural Constraints: The British Approach to Military Transformation', in Terry Terriff, Frans Osinga and Theo Farrell (eds.), A Transformation Gap?: American Innovations and European Military Change (Stanford: Stanford University Press, 2010), p.38.

${ }^{43}$ Sophy Gardner, 'Operation Iraqi Freedom: Coalition Operations', Air \& Space Power Journal (Winter 2004), pp.95-96.

${ }^{44}$ Paget, The Dynamics of Coalition Naval Warfare, pp.209-211.

45 Stephanie Hszieh, George Galdorisi, Terry McKearney and Darren Sutton, 'Networking the Global Maritime Partnership', Naval War College Review, 65:2 (Spring 2012), p.20.

${ }^{46}$ Farrell and Bird, 'Innovating within Cost and Cultural Constraints', p.38.

${ }^{47}$ For more on the command, control, communications, computers, intelligence, surveillance and reconnaissance (C4ISR) challenges, see: Stephanie Hszieh, George Galdorisi, Terry Mckearney and Darren Sutton, Networking the Global Maritime Partnership (Canberra: Sea Power Centre-Australia, 2014).

${ }^{48}$ Paget, The Dynamics of Coalition Naval Warfare, pp.232-233.

${ }^{49}$ Rear Admiral Peter Jones, RAN, interview with author, 27 May 2011.

${ }^{50}$ Rear Admiral Nick Lambert, RN, interview with author, 27 July 2011.

${ }^{51}$ Admiral Tim Keating, USN, interview with author, 31 January 2012.

${ }^{52}$ Costello, Fortune Favors Boldness, p.109.

${ }^{53}$ Ibid.

${ }^{54}$ Vice Admiral Barry Costello, USN, interview with author, 31 July 2011.

${ }^{55}$ D.M. Horner, 'Blamey and MacArthur: The Problems of Coalition Warfare', in William Leary (ed.), We Shall Return!: MacArthur's Commanders and the Defeat of Japan, 1942-1945 (Lexington: The University Press of Kentucky, 2004), p.23. For more on the relationship between MacArthur and Hart, see: John Gordon, Fighting for MacArthur: The Navy and Marine Corps' Desperate Defense of the Philippines (Annapolis: Naval Institute Press, 2011); Richard Connaughton, MacArthur and Defeat in the Philippines (New York: Overlook Press, 2011).

${ }^{56}$ Keating, interview.

${ }^{57}$ Lambert, interview.

58 Michael Smith, 'Doctrine and Training: The Foundation of Effective Coalition Operations', in Thomas Marshall, Philip Kaiser and Jon Kessimer (eds.), Problems and Solutions in Future Coalition Operations (Carlisle: Strategic Studies Institute, December 1997), p.69.

${ }^{59}$ Mario Matos, 'Combined Exercises: A Security Cooperation Tool', The DISAM Journal, December 2007, pp.137-138. 
Steven Paget

Forthcoming in Defense \& Security Analysis, 36:1, 2020. This is the post-print version and must not be copied or cited without permission.

${ }^{60}$ Steve Bowman, 'Historical and Cultural Influences on Coalition Operations', in Thomas Marshall, Phillip Kaiser and Jon Kessimer (eds.), Problems and Solutions in Future Coalition Operations (Carlisle: Strategic Studies Institute, December 1997), pp.3-4.

${ }^{61}$ Anthony Gray, 'International Military Interoperability Summit Emphasizes Role of the FAO', FAOA Journal of International Affairs, 16:3 (Fall 2013), p.17.

${ }^{62}$ It should be recognised that the 'transient nature' of personnel means that some experience derived from exercises is inevitably lost, but OIF demonstrated that the presence of even a small number of personnel with prior experience of coalition partners can provide significant benefits. Michael Spirtas, Jennifer D. P. Moroney, Harry J. Thie, Joe Hogler and Thomas-Durell Young, Department of Defense Training for Operations with Interagency, Multinational, and Coalition Partners (Santa Monica: RAND, 2008), p.33.

${ }^{63}$ Marvin Pokrant, Desert Storm at Sea: What the Navy Really Did (Westport: Greenwood Publishing Group, 1999), p.268.

${ }^{64}$ Mark Lawrence, Tailoring the Global Network for Real Burden Sharing at Sea (Washington, DC: Center for Strategic and International Studies, 2015), p.14.

${ }^{65}$ John Deni, 'Maintaining Transatlantic Strategic, Operational and Tactical Interoperability in an Era of Austerity', International Affairs, 90:3 (2014), p.594.

${ }^{66}$ Costello, Fortune Favors Boldness, p.91.

${ }^{67}$ Captain John Peterson, USN, second interview with author, 3 September 2011.

${ }^{68}$ There are exceptions to the rule such as the Royal Canadian Navy, which maintains a high level of interoperability with the five eyes navies, especially the USN.

${ }^{69}$ Sarandis Papadopoulos, 'The Combined Framework: How Naval Powers Deal with Military Operations Other Than War', in Gary Weir and Sandra Doyle (eds.), You Cannot Surge Trust: Combined Naval Operations of the Royal Australian Navy, Canadian Navy, Royal Navy, and United States Navy, 1991-2003 (Washington DC: Naval History and Heritage Command, 2013), p.6.

${ }^{70}$ Joel Sokolsky, Seapower in the Nuclear Age: The United States Navy and NATO, 1949-1980 (London: Routledge, 1991), p.97

${ }^{71}$ Anthony Rice, 'Command and Control: The Essence of Coalition Warfare', Parameters (Spring 1997). Copy available from US Army, <https://ssi.armywarcollege.edu/pubs/parameters/articles/97spring/rice.htm> (accessed 2 May 2018).

${ }^{72}$ Eric Lehre, At What Cost Sovereignty? Canada-US Military Interoperability in the War on Terror (Halifax: Centre for Foreign Policy Studies, 2013), p.5.

${ }^{73}$ Peter Jones, 'Militarization in the Pacific', in Ranginui Walker and William Sutherland (eds.), The Pacific:

Peace, Security \& the Nuclear Issue (London: Zed Books, 1988), p.55.

${ }^{74}$ Commodore Peter Lockwood, RAN, interview with author, 5 May 2011.

${ }^{75}$ Combined Review Team, Review of Operational Level Interoperability Between the Military Forces of Australia and the United States of America, p.33.

${ }^{76}$ Jeffrey G. Barlow, 'The U.S. Navy's Role in Coalition Maritime Interception in Operation Enduring Freedom, 2001-2002', in Gary Weir and Sandra Doyle (eds.), You Cannot Surge Trust: Combined Naval Operations of the Royal Australian Navy, Canadian Navy, Royal Navy, and United States Navy, 1991-2003 (Washington DC: Naval History and Heritage Command, 2013), p.184.

${ }^{77}$ Robert Rubel, 'Posture Versus Presence: The Relationship between Global Naval Engagement and Naval WarFighting Posture', Naval War College Review, 69:4 (Autumn 2016), p.22.

${ }^{78}$ Peterson, second interview.

${ }^{79}$ NGS was provided by Anzac and HM Ships Chatham, Marlborough and Richmond.

${ }^{80}$ Major Peter Boyce, Royal Artillery (V), interview with author, 15 December 2011.

${ }^{81}$ Lockwood, interview.

${ }^{82}$ Lieutenant General Jim Dutton, Royal Marines, interview with author, 22 July 2011.

${ }^{83}$ Peter Jones, 'In the Wake of an Admiral: Some Reflections on Sea Command in the Modern Era', Australian Defence Force Journal, 184 (2011), p.24.

${ }^{84}$ Lockwood, interview.

85 'Open Forum', in John Mortimer and David Stevens (eds.), Presence, Power Projection and Sea Control: The RAN in the Gulf, 1990-2009 (Canberra: Sea Power Centre-Australia, 2009), p.91.

${ }^{86}$ Costello, Fortune Favors Boldness, pp.113-114. 
Steven Paget

Forthcoming in Defense \& Security Analysis, 36:1, 2020. This is the post-print version and must not be copied or cited without permission.

${ }^{87}$ Jones, 'Task Group Command, 1990-2003', p.82.

${ }^{88}$ James Goldrick, 'Task Group Command, 1990-2003', in John Mortimer and David Stevens (eds.), Presence, Power Projection and Sea Control: The RAN in the Gulf, 1990-2009 (Canberra: Sea Power Centre-Australia, 2009), p.73.

${ }^{89}$ Mekonya Cheefus, 'O Canada!', Warrior-Citizen, 53:2 (Spring 2008), p.30.

${ }^{90}$ United States Navy Personnel Command, 'PEP', 30 December 2014, <http://www.public.navy.mil/bupers-npc/career/language_culture/Pages/PEP.aspx> (accessed 2 May 2018).

${ }^{91}$ Gary McHugh, 'US Exchange Submariners Right at Home in the West', Navy Daily, 9 April 2014, $<$ http://news.navy.gov.au/en/Apr2014/People/978/US-exchange-submariners-right-at-home-in-thewest.htm> (accessed 2 May 2018).

${ }^{92}$ Rear Admiral James Goldrick, RAN, interview with author, 4 August 2011.

${ }^{93}$ Rear Admiral Mark Anderson, RN, interview with author, 13 July 2011.

${ }^{94}$ Jones, interview.

${ }^{95}$ Ibid.

${ }^{96}$ Commodore Phil Spedding, RAN, interview with author, 12 August 2011.

${ }^{97}$ Rear Admiral David Snelson, RN, interview with author, 20 June 2011.

${ }^{98}$ See: Steven Paget, "'Interoperability of the Mind": Professional Military Education and Development of Interoperability', The RUSI Journal, 161:4 (September 2016), pp.42-50.

${ }^{99}$ Lockwood, interview.

${ }^{100}$ A retired RN officer, interview with author, 19 November 2011.

${ }^{101}$ Febbraro, McKee and Riedel, 'Multinational Military Operations and Intercultural Factors', p.3-8.

102 Tim Blad and David Potts, 'Beyond Interoperability: Part 1', in David Potts (ed.), The Big Issue: Command and Combat in the Information Age (Shrivenham: Strategic \& Combat Studies Institute, March 2002), pp.146.

${ }^{103}$ Jones, 'Task Group Command', p.81.

${ }^{104}$ Admiral Sir James Burnell-Nugent, RN, interview with author, 14 November 2011.

${ }^{105}$ Jones, interview.

${ }^{106}$ Costello, Fortune Favors Boldness, p.70.

${ }^{107}$ Commander Steve Aiken, RN, interview with author, 17 January 2012.

${ }^{108}$ Peterson, first interview.

${ }^{109}$ David Crist, 'The Formation of a Coalition of the Willing and Operation Iraqi Freedom', in Bruce Elleman and S.C.M. Paine (eds.), Naval Coalition Warfare: From the Napoleonic War to Operation Iraqi Freedom (Oxford: Routledge, 2008), pp.212-213.

${ }^{110}$ Peterson, first interview.

${ }^{111}$ Captain Peter Leavy, RAN, interview with author, 15 September 2011.

112 Jones, 'Task Group Command, 1990-2003', p.82.

${ }^{113}$ Costello, interview.

114 Mass Communication Specialist 3rd Class Andrew Murray, 'Dutch Navy Commodore Visits USS Fort McHenry During Cold Response 2016', 9 March 2016, <http://www.navy.mil/submit/display.asp?story_id=93538> (accessed 2 May 2018). 